\title{
EFFECTS IN HEALTH AND DISEASE
}

OF SOME

\section{DRUGS WHICH CAUSE RETENTION OF URIC ACID,}

IN CONTRAST WITH THE ACTION OF SALICYLATES, AS

SHOWN IN A PREVIOUS PAPER.

BY

A. HAIG, M.A., M.D.Oxon., M.R.C.P.

Received February 14th-Read April 24th, 1888.

IN a paper recently read before the Society (January 10th, 1888) I have shown that a large part of the value of salicylic acid and its salts in disease is probably due to their facilitating the excretion of uric acid by forming a compound with it which is soluble in slightly acid fluids, that they thus not only directly increase excretion but also prevent acids from causing retention. For, as I have reason to believe that several of the more important diseases connected with uric acid are directly due to the retention of this substance in the body, occasioned for the most part by acids, ${ }^{1}$ anything that will prevent acids from diminishing the solubility of uric acid and thus causing retention will have great power both to prevent and cure such diseases; hence the importance which I attach to my results obtained with salicylates as brought forward in the above paper.

\footnotetext{
1 'Journal of Physiology,' vol. viii, Nos. 3 and 4.
} 
I now propose to contrast with the above-mentioned action of salicylates that of several drugs which cause retention of uric acid, and to inquire how far such drugs are known to do harm in the diseases where salicylates are beneficial.

Lead.-It will be seen by the curves in Fig. 1 that the metal taken as the acetate causes clearly and distinctly

FIG. 1.

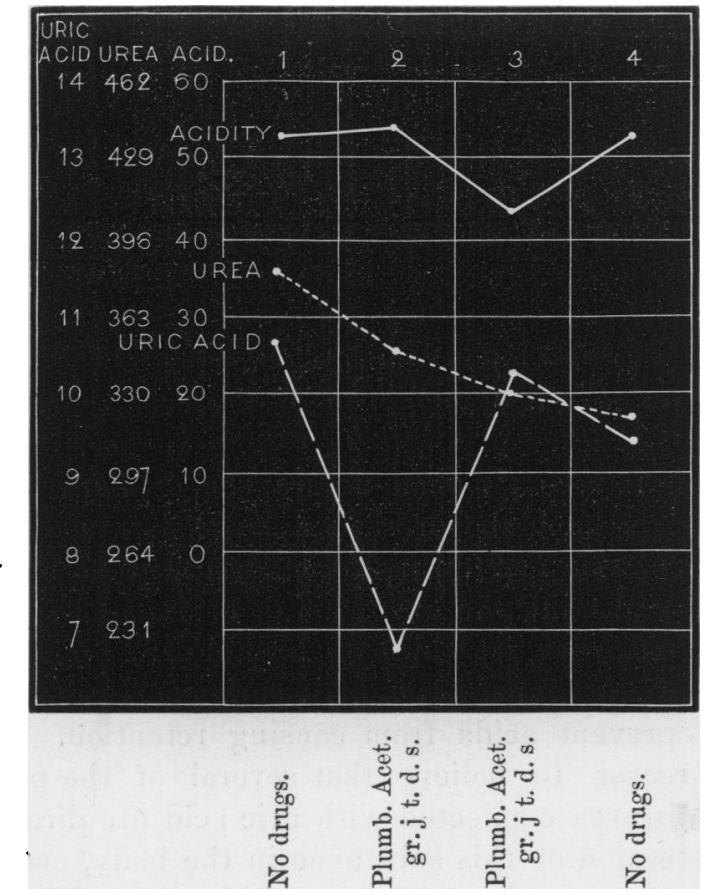

retention of uric acid, the uric acid falling below the urea to the extent of some three and a half grains on the first day of taking the drug; and I may say that this experiment has been several times repeated and always gives this result. On the second day, however, uric acid rises above urea, and there is no retention, and this is the result 
of several causes and does not in the least show any failure of action on the part of the lead. First of all, urea has fallen and acidity has fallen very considerably, and this alone would account for some rise of uric acid excretion. The fall of urea and acidity are probably due to the interference of the lead with intestinal digestive processes, and this also is a constant result of taking this salt. Again, as I have said in the ' Journal of Physiology,' acids appear to be able to cause retention only up to a certain point, and after some five grains or so have been deposited in the liver, spleen, \&c., it is difficult to cause any further retention by the use of acids. Now, there is reason to think, from the curves shown, that at the time lead was taken in this figure there was already a considerable accumulation of uric acid in the liver, spleen, \&c., so that both the causes I have mentioned may have prevented retention by lead on the second day it was taken.

It may be asked why I did not continue the lead in the above curves so as to obtain further proof of its causing retention? My reason was this, that as soon as lead begins to interfere with intestinal processes so many factors are brought in that the problem becomes too complex to be of any value; thus the results of intestinal irritation, dyspepsia, flatus, diarrhœa, caused by any drugs of irritant nature, are a fall in urea and acidity. The result of falling acidity is a rise in the uric acid excretion, so that it becomes impossible to say what action the drug may have on uric acid excretion. There are several drugs which quickly cause intestinal irritation, and whose action on uric acid excretion (if any) it is therefore impossible to make out with certainty. This would be the case with lead except for the fact that it appears to act on uric acid excretion at once, but in the doses taken it only appreciably affects digestive processes after some twenty-four hours.

Iron.-It will be seen in Fig. 2 that this causes marked retention, but, unlike lead, its greatest effect takes twenty-four hours to come out. Possibly, the greater 
solubility of the lead salt used may account for its quicker action. As soon as the iron is left off the uric acid rushes out in excess.

FIG. 2.

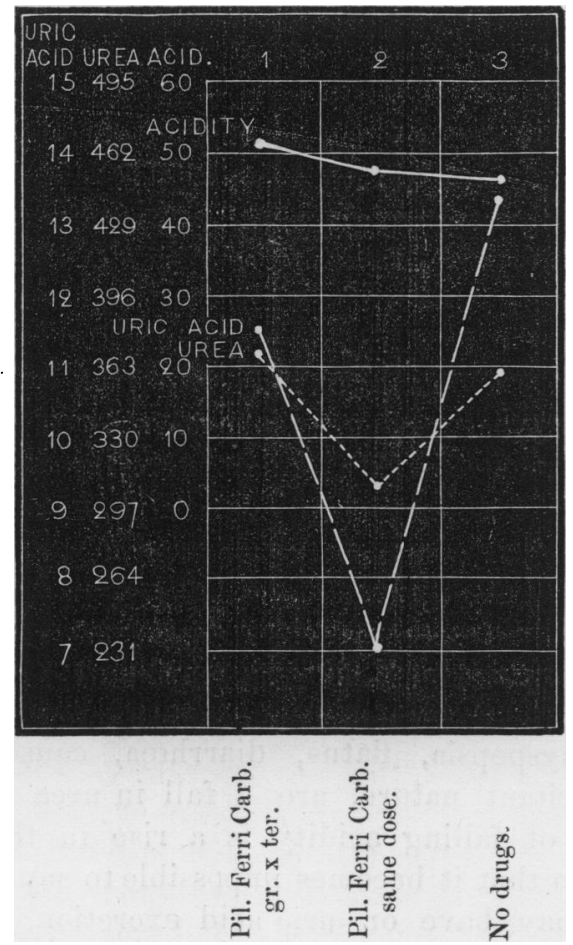

Urates of lead and iron are said by Sir A. Garrod to be quite insoluble; and this fact affords, I believe, the explanation of their action in causing retention. For, if salicylates form a soluble compound with uric acid and so facilitate its excretion, it is reasonable to suppose that if these metals form insoluble compounds with it they would prevent excretion and cause retention.

Lithium.-Here we have a drug whose urate has been shown by $\operatorname{Sir}$ A. Garrod to be extremely soluble, and yet 
Fig. 3 shows, as I believe, that it causes retention of uric acid. When I first noticed this action of lithia salts I thought it must be an error, but repeated experiments showed me that the result was invariable; and I was then

Fig. 3.

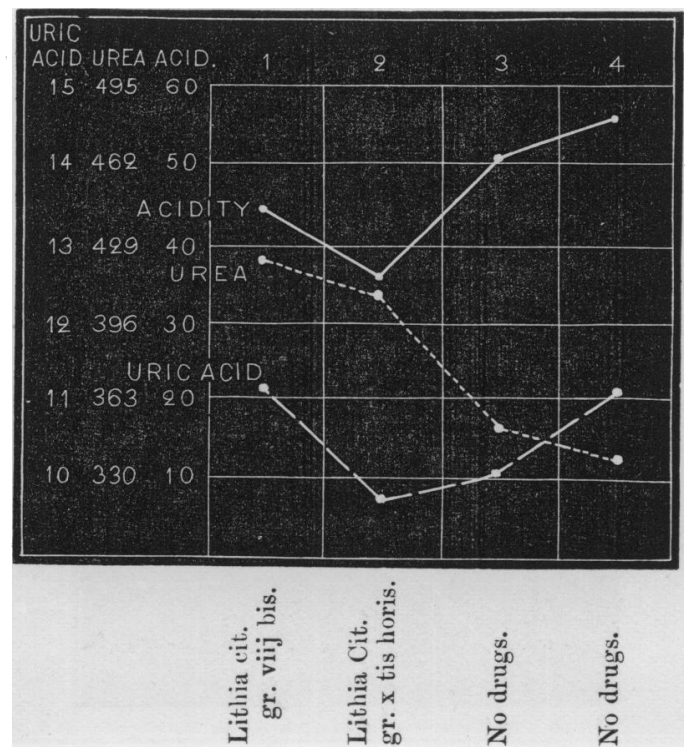

inclined to conclude that this was a fatal blow to the theory of the solubility of the compounds formed as the cause of uric acid excretion or retention, for how could a metal whose urate is the most soluble of all urates yet cause retention of uric acid?

There could be no doubt as to the great solubility of urate of lithia, and I could see no way out of the difficulty in that direction.

Thanks, however, to Dr. Neale's ' Digest,' I found a reference to the 'Lancet' twenty-eight years ago, which said that lithia was no use as a solvent of uric acid when taken by the mouth, and on looking up this reference I found the following statements ('Lancet,' ii, 1860, p. 185) : 
"Mr. Ure does not recommend the internal use of this salt (carbonate of lithia) in the treatment of vesical calculus for the reason that it would undergo decomposition and precipitation when coming in contact with ammoniophosphate of soda, and thereby be rendered 'inert.'

FIG. 4.

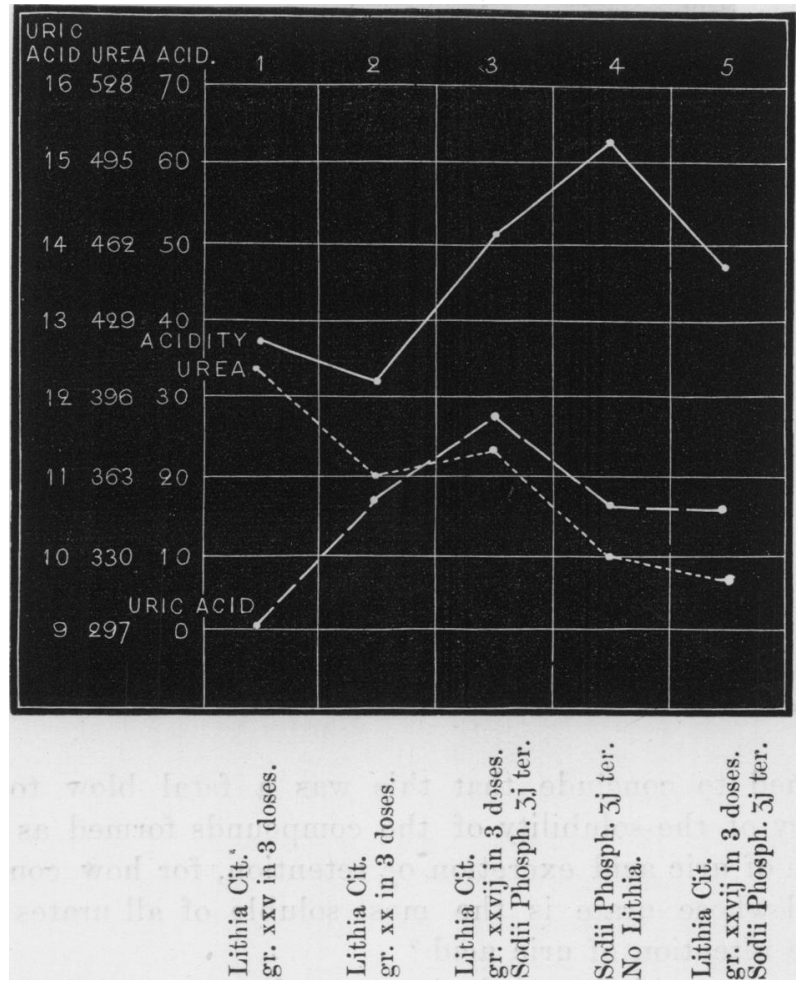

Given internally it forms a nearly insoluble triple phosphate with phosphate of soda, or with the triple phosphates of ammonia and soda, salts generally present in animal fluids. Lithia solutions differ in this respect from those of soda and potash."1

1 Rose, 'Chemical Analysis,' p. 15. 
The insoluble lithia phosphate above mentioned is, I believe, well known to chemists, and if we may take the chemical explanation as correct, it is easy to see that lithia taken internally not only never reaches the uric acid to form a soluble urate, but in forming an insoluble compound with phosphate of soda it practically removes from the blood one of the well-known solvents of uric acid; and Fig. 4 shows, I think, that sodium phosphate taken in one-drachm doses three times a day, prevents lithia causing any retention, i.e. it supplies the place of the sodium phosphate removed by combination with the lithia, so that after all there is here no exception to the rule of solubility. I have now shown that three drugs, lead, iron, and lithia, when taken internally, cause retention of uric acid either by forming insoluble compounds with it or, as in the case of lithia, by removing one of its natural solvents ; and I now propose to look at what is known of their action in disease.

With regard to lithia I have very little to say. It was at one time much used, then fell into disuse, and has finally been brought forward again, in the treatment of uric acid disease, but there is by no means a unanimous opinion as to its value at the present day, and to quote ${ }^{1}$ some recent writings, Dr. Yeo says of it, "For my own part I am disposed to think we are nowadays inclined to exaggerate the value of the lithium compounds as compared with those of potash and soda," and he qnotes Ebstein, Sir W. Roberts, and Lecorché as doubting its efficacy, or preferring other alkalies, and he mentions that Ebstein asserts that chloride of lithium has no solvent action on uric acid.

I have above spoken several times of the action of dyspepsia, and it has some interesting connections in the causation of headache, and I believe also in that of epilepsy, gout, and other members of the group, of which I may here say a few words. 
In headache, the usual sequence is as follows :-There is a time (say seven to ten days) of good general health, active nutrition and bodily activity, with plus formation of uric acid and urea, and concomitant rise in acidity. As acidity rises, uric acid comes to be retained, and at the end of four or five days several grains may be regarded as stored up in the liver and spleen. Then come dyspepsia, gastro-intestinal catarrh, and hepatic congestion (and I am not by any means certain that this hepatic congestion and gastro-intestinal trouble may not be the direct result of the accumulation of uric acid in the liver and spleen). These quickly result in general diminution of absorption and nutritive changes, with lessened formation of uric acid and urea and a fall in acidity; and lastly, as the result of this falling acidity, there comes a rush of the stored uric acid into the blood and the headache begins. Such a sequence may be seen to some extent in the figure that accompanies my paper on headache ('Transactions,' 1887), for there the urea drops from 561 grains to 363 grains in the four days that immediately precede the headache. Although acidity was not estimated in this instance there can be no doubt that it followed and shared in the fall of urea to a large extent. Snch a sequence explains the periodicity of this kind of headache, and the way in which it ${ }^{1}$ comes to occur every week or ten days for many years, varying only in degree with the corresponding variations in nutrition. It is also evident that any causes which affect digestion will influence the attack in one of the above ways; while all causes of debility, by weakening the nerve-centre on which the uric acid acts, will render it more sensitive (the reverse of the action of bromides) and the attacks more frequent. A knowledge of these facts gives me almost complete power either to cause or cure this headache in myself and other sufferers. Further, I believe it will be found that dyspepsia bears a similar causative 
relation to the attack of gout, epilepsy, and other members of the group, and that the conditions affecting the nervecentres act in epilepsy just as in headache.

With regard to lead, I stand on very firm ground, for Sir A. Garrod has shown that it diminishes the excretion of uric acid; and he has also shown that, given medicinally, it will precipitate attacks of gout; further he records the fact that in lead-poisoning the blood almost invariably contains uric acid.

Dr. Ross also speaks of chronic lead-poisoning as a cause of epileptic convulsions, and Mr. Pepper, in the 'Lancet' of Nov. 5th, 1887, makes some interesting remarks on lead as a cause of epilepsy, which he regards as curious or even mysterious; but $I$ cannot see that there is any mystery about it once we know that epilepsy may be (as I shall attempt to show farther on) due to uric acid, as we can then at once understand that the bad effects of iron and lead may result from the retention of uric acid they occasion.

Sir A. Garrod ${ }^{3}$ has pointed out that iron given soon after an attack of gout will cause a relapse, and $M$. Brown-Séquard ${ }^{4}$ says that iron does harm in many cases of epilepsy; it has also appeared to me to be harmful in some cases of headache due to uric acid, ${ }^{5}$ so that I have several times been led to look for uric acid as a cause, from the fact that iron did harm.

With regard to salicylates in gout, though some have expressed doubts of their value, and though Dr. Yeo speaks somewhat unfavorably of them, many of the opinions he quotes are strongly in their favour. Some, while acknowledging their value in the disease, refuse to give them on account of their depressant action, or some harm they may do to the kidneys.

1 Garrod, 'Gout and Rheumatic Gout,' 3rd edit., p. 237, et seq.

'Ross, 'Diseases of the Nervous System,' vol. ii, p. 915.

' 'Brit. Med. Journ.,' i, 1883, p. 705.

4 Quain's 'Dictionary of Medicine,' p. 450.

5 “Uric Acid Headache," ‘St. Bartholomew's Reports,' 1887.

- ‘ Brit. Med. Journ.,' i, 1888, p. 67. 
From what I know of their action on the uric acid excretion I should not expect them to have a very prompt curative effect in acute gout, though, taken for some time, I should expect them to prevent attacks, ${ }^{1}$ so that some unfavorable opinions may be due to their slow action in acute cases (see especially the opinion of Lecorché, quoted by Dr. Yeo, as to their power in prevention).

In explanation of the references made to epilepsy, I may say that $I$ have shown in a paper in the ' Neurologisches Centralblatt' of March 1st, 1888, that some cases of epilepsy will yield uric acid reactions which are practically identical with those I have obtained in the case of headache, ${ }^{2}$ so that if some headaches are due to uric acid some epileptic fits are also due to it, and the fits in these cases can probably, like the headaches, be prevented by treatment directed to the uric acid factor.

Just as the clinical relationship of headache to gout led me to examine the urine in headache, so the strong clinical relationship of epilepsy both to headache and gout ${ }^{3}$ led me to expect, what I have now found, a similar uric acid reaction in each.

All epileptic fits are not due to uric acid any more than all headaches are; but I expect that it will eventually be shown that those cases of epilepsy which have a wellmarked family history of gout, rheumatism, headache, or epilepsy will give uric acid reactions, and be cured by treatment directed to the uric acid factor, just as in the case of the corresponding headache; and it is in such cases of epilepsy that iron will do harm, that lead may be expected to precipitate attacks, and that salicylates will prevent them. And I believe that it may eventually be possible to show that salicylates do prevent the fits in such cases, as well or better than bromides.

If any of those who are interested in the pathology and

1 'Proc. Roy. Med. and Chir. Soc.,' Jan. 10th, 1888, N. S., vol. ii, p. 327.

2 'Med.-Chir. Trans.,' vol. lxxi.

3 Paper on Headache, ‘St. Barth. Hosp. Rep.,’ 1887. 
treatment of epilepsy should feel inclined to investigate the matter from this point of view, I would suggest the following method, which I now use myself :-Take a case of idiopathic epilepsy where, as in the case of the corresponding headaches, the fits have begun early in life and lasted for many years, where there is also a marked family history of gout, rheumatism, headache or epilepsy. The fits in such a case may be due to uric acid, and the point may be tested as follows :-If the fits are due to uric acid in the blood, drugs which prevent accumulation (retention) of uric acid will prevent the fits. Now, salicylates are, for the reasons I have given, probably the best of all drugs to prevent retention of uric acid; so that in the supposed case if salicylate of soda is given in doses sufficient to prevent any retention of uric acid (say ten grains for a child, or fifteen to twenty for an adult, three times a day) excess of uric acid in the blood will be almost impossible, and the fits will be completely absent so long as the salicylates are kept up and are absorbed. Where such immunity occurs, I should consider that it practically proves the fits to have been due to uric acid; but if there is any doubt a uric acid reaction taken during a fit will settle the question. ${ }^{1}$

In cases which have been tested as above by salicylates, or where uric acid reactions have been obtained, there is, I think, no doubt that the diet which I have found so useful in headaches due to uric acid, will in course of time afford what is practically complete immunity from fits, and cases cured by vegetable diet are not very rare (see my paper in 'St. Bartholomew's Hospital Reports' for 1887, p. 211).

And if salicylates can prevent these fits by preventing retention of uric acid, it is surely no very extraordinary thing that iron and lead, which cause retention, should occasionally produce fits as they have been observed to do.

And there is one further point about epilepsy, for a 1 'Neurologisches Centralblatt,' March 1st, 1888. 
reference to which I am indebted to Sir Dyce Duckworth, viz., that Dr. Radcliffe $e^{1}$ has noticed that by giving Potassium Iodide and Potassium Bicarbonate along with bromides he was able to give less bromide. Thus he says, "About the advantages of associating iodide of potassium and bicarbonate of potassium with ordinary bromides in the treatment of epilepsy, I cannot speak so positively as about the disadvantage of associating iron with them ;" and further on he says, "I am inclined to think that less bromide will serve to produce a good result with this addition (iodide and bicarbonate) than without it. To this conclusion I am constantly led by the results of experience."

The explanation of this observation is quite simple, for I have shown in the 'Journal of Physiology' that alkalies facilitate the excretion of uric acid and prevent retention, and if alkalies are steadily given along with bromides there will never be any great accumulation of uric acid in the liver and spleen or a great excess of it in the blood; hence a smaller dose of bromide will serve to prevent the nerve-centres from reacting to the irritant. Dr. Radcliffe's remarks about iron, and also some other remarks in the same paper about diet in epilepsy, are of great interest from my point of view, and tend to confirm my explanation of its causation.

And I believe that very much of the same reasoning will apply to some important points in the etiology of gout into which there is no space to enter here; for instance, several writers on this subject speak of small temporary hindrances to uric acid excretion as causative of attacks. Thus Liebermeister, speaking of gout, says, ${ }^{2}$ "In manchen Fällen scheint eine temporäre Behinderung der Ausscheidung durch die Nieren die Gelegenheitsursache des Anfalls zu sein," and a rise in acidity gives us just such a "temporäre Behinderung," though the fault is not in the kidneys themselves; but if salicylates are present in the circulation the rise in acidity will no

1 'Practitioner,' 1883, vol. xxx, p. 95.

2 'Vorlesungen über Special Pathology u. Therapie,' vol. iii, p. 38. 
DRUGS WHICH CAUSE RETENTION OF URIC ACID. 295

longer have power to cause retention of uric acid, and thus an attack of headache, epilepsy, or gout will be prevented.

(For report of the discussion on this paper, see 'Proceedings of the Royal Medical and Chirurgical Society,' New Series, vol. ii, p. 377.) 